\title{
DESIGN AND EXPERIMENTAL INVESTIGATION OF AN ELECTRONICS SPRAY DRYER PROCESS CONTROL
}

\author{
Andriani Parastiwi ${ }^{1 *}$, Ekojono ${ }^{1}$, Bambang $\operatorname{Irawan}^{1}{ }^{1}$, Cahya Rahmad ${ }^{1}$, \\ Achmad Komaruddin ${ }^{1}$ and Tutut Herawan ${ }^{2}$ \\ ${ }^{1}$ Politeknik Negeri Malang, Indonesia \\ ${ }^{2}$ Sekolah Tinggi Pariwisata Ambarrukmo, Indonesia \\ *parastiwi@polinema.ac.id
}

\begin{abstract}
Spray drying technology is an effective postharvest process for making fruit and vegetable powders with long shelf life. In general, spray dryer machine needs electricity energy for more than $5 \mathrm{KW}$ which can't be afforded by farmer community. In this study, low electricity energy spray drying machine was designed for farmer community. The machine use food grade stainless steel with the combination of electrical energy and liquid petroleum gas (LPG) energy. Electrical energy is used for electronics control system and air compressor, whereas LPG energy use for heat exchanger for the drying chamber. The electronics process controller is implemented to convert fresh fruit or vegetable into a fruit or vegetable powder form of a desired quality at a minimum cost. A simulation of a PID controller with Ziegler- Nichols tuning in the form of an Excel spreadsheet give the parameters used for the machine. Experiment was done to produce tomato powder from fresh tomato, whereas air inlet temperature of $150^{\circ} \mathrm{C}$, the pressure of $3 \mathrm{bar}$ and hot air outlet set to $100^{\circ} \mathrm{C}$ with the addition of Maltodextrin $40 \mathrm{~mL} / \mathrm{Liter}$ has increase the powder quality, however adding more Maltodextrin make the tomato powder has less natural flavor. Increasing hot air temperature make the powder quality increase, in contrary the energy consumption of making the powder increased.
\end{abstract}

Keywords - Power electronics; Temperature control; Spray dryer; Experimental

\section{INTRODUCTION}

The potential of natural resources in Malang, Indonesia, is surrounded by active mountains has made Malang as an agribusiness center for fruit and vegetable. However, fluctuations in the price of fruit and vegetables is generally higher due to an imbalance between the volume of supply and consumer needs [1]. Such conditions are not conducive to developing agribusiness due to the inability to respond to market dynamics. In this study, the drying machine has been designed providing a means of processing of vegetables and fruits by the use of energy that is not too large, so when the market is unable to absorb the products of vegetables and fruits produced by farmers and farmer communities, farmer community can produce fruits or vegetables powder as a natural food that can be sent to a wider area with a higher price. Some study on natural fruit and vegetable powder production is reported more beneficial [2-4]. This effort on designing dryer machine is aligned with Indonesia Higher Education Research Roadmap that one of the topics was the field of poverty reduction and business policies [5].

Received: April 8, 2019

Reviewed: June 19, 2019

Accepted: July 23, 2019

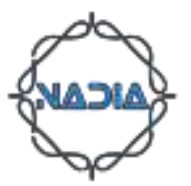


On the other hand, the public is increasingly enjoyably natural foods. Increasingly complex pattern of life that makes it difficult to keep fresh natural food, because the durability of fresh food is relatively short. Demand extract (instant powder) of fruits and vegetables naturally (tomato powder, carrot powder, orange powder, etc.,) is increasing. This opens up new opportunities for producing natural fruits and vegetables powder. One way to make a natural food powder from fruits and vegetables is by drying with a spray dryer machine. Spray dryer machines available on the market are expensive and require high energy (kilo Watt) for operations that could not be attempted by farmers-community who are mostly poor farmers. Therefore, the farmers-community required spray dryer machine that can operate with minimal energy. Problems tries to convey its solution is how to design and develop an optimal spray dryer machines but can be operated with minimal energy as a means for poverty alleviation in particular fruits and vegetables farmers-community in the processing of agricultural products during harvest and not absorbed by the market. In this way, the conservation of a fresh fruits and vegetables in the form of powder can be done using spray dryer machine.

Spray dryer machine is a device to produce powder-form from a mixture of liquidform. The liquid mixture usually being sprayed into a hot dry air in a chamber which will remove the moist of the liquid. In the spray drying process, the water vapor is separated from the liquid so that the resulting powder will be remains in the bottom of the chamber.

Spray dryer chamber has one vapor form of the liquid inlet, a hot air outlet, and a powder outlet. The main challenge in controlling the spray dryer chamber is to use minimum of energy consumption to bring the powder not sticks to the wall of the chamber or to produce a powder with a certain amount of moisture. The large amount of water on the vapor form of the liquid inlet need to be evaporated. The energy consumption on the spray dryer chamber has been extended observed [6-9].

The biggest challenging problem to be solved in this study is energy consumption. The small existing laboratory spray dryer operate by more than $5 \mathrm{KW}$ electricity power source. This big electricity power consumption for a machine is still a big problem for Indonesia regular farmers-community. Therefore, the combination of electricity power source and liquid petroleum gas is used in the design of the spray dryer machine. The liquid petroleum gas is commonly used in Indonesia and the price is cheaper than electricity power. Hot air is gained from a liquid petroleum gas burner, whereas air-pump and electronics controller using electricity power. The most important of the energy consumption improvement on spray dryer mostly is the temperature controller design strategy. The preliminary spray dryer design has been done extensively for two years especially on the temperature electronics controller, the deep discussion on the results are outlined based on the study.

This paper is organized as in Section 2 provides the introduction to spray dryer technology and existing spray dryer machines on the market. Whereas Section 3 provides temperature electronics controller, and Section 4 provides the methodology. In addition, Section 5 discusses the findings and finally Section 6 provides the conclusions.

\section{SPRAY DRYER TECHNOLOGY AND THE EXISTING SPRAY DRYER ON THE MARKET}

Spray dryer technology is a drying method most widely used in industry, especially in food industry. This method is able to deliver products in the form of powder or powder materials such as milk, fruits, and so forth. The parts of the spray dryer unit consist of feed pump; atomizer, air heater; air disperser; drying chamber; powder recovery system; air purifier output; and a cyclone [10]. 


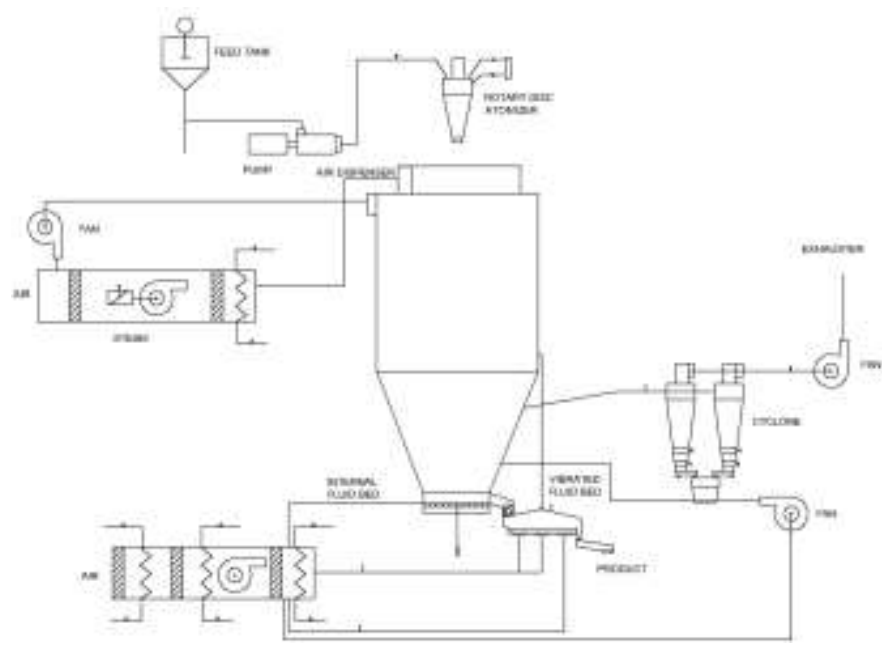

Fig. 1 Spray Dryer Machine [10]

The principle of spray dryer machine is first the fruits or vegetables to be dried are blend with water to get a slurry which is placed in the feed tank. The droplet of this slurry is mixed with air to be high pressure slurry blown into the dryer chamber through rotary disc atomizer. On the other hand, hot air inlet blown into the dryer chamber through the air dispenser inlet.

Slurry from the material that has been shaped droplets are contacted with hot air. These events led to contacting the slurry in the form of droplets to dry and turn into powder. Furthermore, the process of separation between the hot slurry with powder carried by a cyclone or filter. Once separated, the powder then returned lowered the temperature in accordance with the needs of production, as shown in Figure 1.

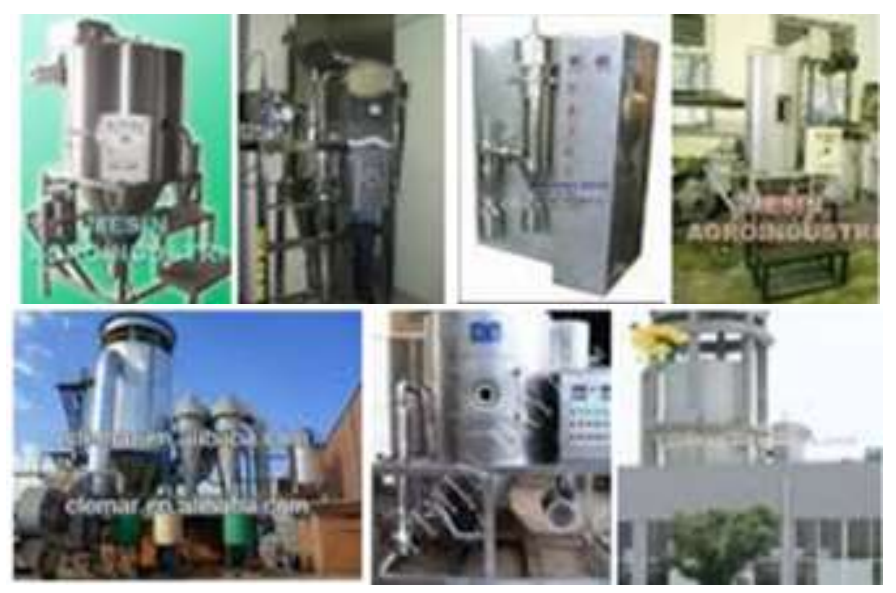

Fig. 2 Spray Dryer Machine on Online Market

Spray dryer machine on the market varies greatly, as shown in Figure 2. Spray dryer machine sold online come from various countries and there is also a local machine shop made in Indonesia at a price of $\$ 10,000$ to $\$ 100,000$, but in general the electricity energy used on average above $22 \mathrm{KW}$. This $22 \mathrm{KW}$ electricity energy is difficult to be implemented by the farmers-community nor small agribusiness. In addition this machine is too expensive to be bought and difficult in the usage. This raises the need for a spray dryer machine that can produce fruits and vegetables powders which is energized as small as possible.

Engineering Laboratory Scale Spray Dryer of Armfield made in England (as seen in Figure 3) using a heat-resistant glass construction that is suitable for producing powdered 
drinks, extracts of fish, milk and eggs, and also for fruit and vegetable powder. The dimensions of the equipment are the length and width of $50 \mathrm{~cm}$ with $110 \mathrm{~cm}$ height. The weight of this equipment is $190 \mathrm{~kg}$. Slurry flow is $0-1500 \mathrm{ml} /$ hour with 3000 Watt heaters capable of providing heat to $200^{\circ} \mathrm{C}$ and air compressor 50liter/min @ 8bar (with electricity power $2200 \mathrm{Watt}$ ) produces hot air $70 \mathrm{~m}^{3} /$ hour. In others, it is still no more necessity to rotate the electric motors and the motor atomizer. The total electricity power consumed is estimated 5600Watt equipment.

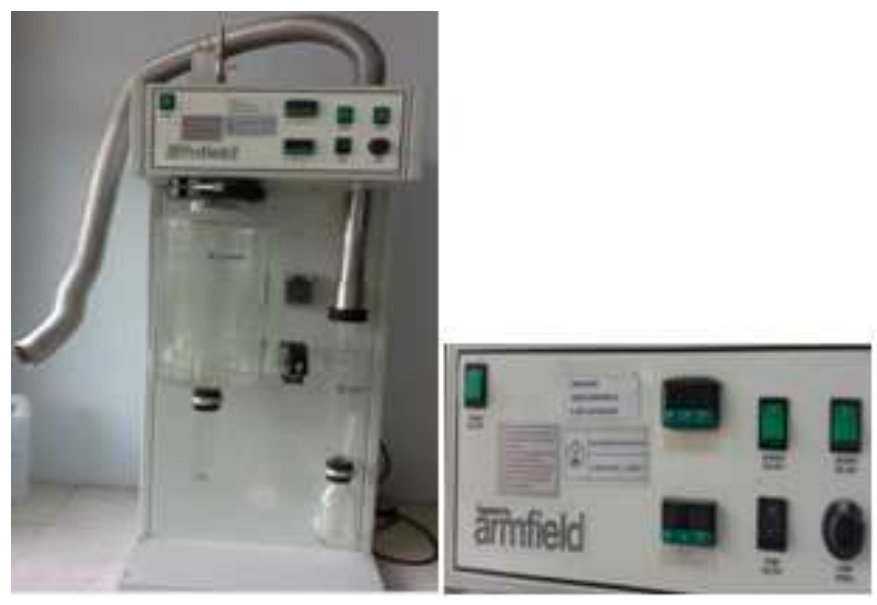

Fig. 3 Laboratory Scale Spray Dryer Machine from Armfield England

The nearly equal machine to the dryer spray machine is instant ginger maker and extractor machine as seen in Figure 4, both machines are widely used by small industries powder drinks in Indonesia. This instant ginger machine is used to cook ginger-liquid and stir the liquid. The process works of this machine is to cook and stir the ginger liquid where the raw materials are sugar, juice of ginger or other spices. The working principle of this machine is to cook the sugar until melted and mixed and stirring the liquid sugar and spice ginger juice. After the crystallize sugar solution spice back earlier to form the instant powder, it is ready to be packed, either by the bottle or container with a packing machine sachet. The total dimensions: 50x70x160cm with driving Electromotor 2HP1Phase, transmission pulley-gear box and heating LPG, food grade stainless-steel 304 and the volume of tube capable of processing materials up to 50 liters or $15 \mathrm{~kg}$ (granulated sugar plus ginger).

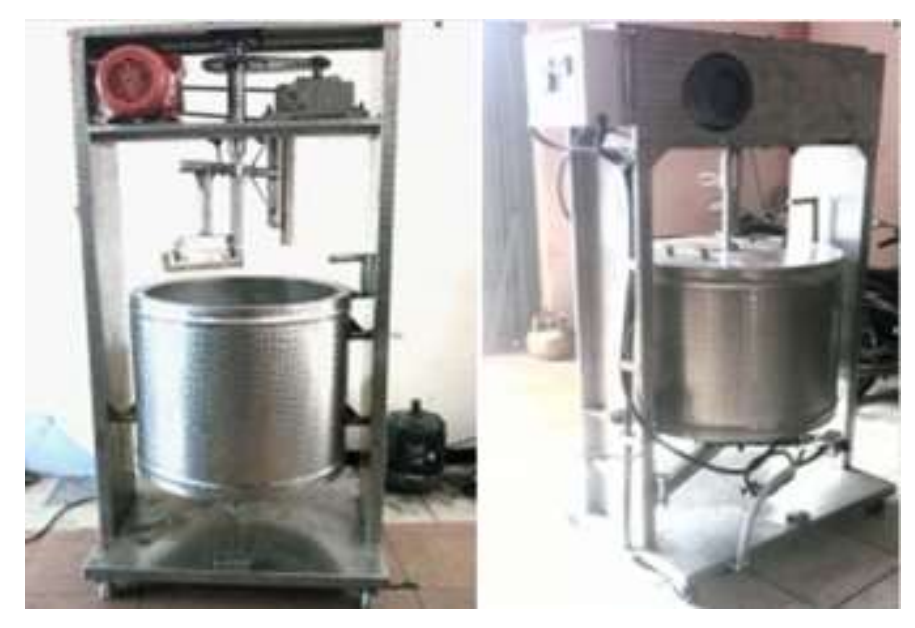

Fig. 4 Instant Ginger Machine and Extractor Machine 
As for the extractor machine is used to thicken honey, fruit extract, or make another extraction. Tubes can be cast with a stirrer of the top lid with a vacuum pump and drive motor 1HP1PK with production capacity of up 100Liter. These two machines principle are used as design consideration in this study.

\section{TEMPERATURE ELECTRONICS CLOSED LOOP CONTROLLER}

Spray drying is the process of converting a mixture in its liquid form to a powder form, which is done by removing the moisture component from the liquid solution. The solution, sometimes called an slurry, is sprayed through a nozzle into a heating chamber with hot air simultaneously being blown into it. The hot air temperature in the heating chamber has to be maintained stable to increase the powder quality and to minimize the energy consumption $[3,6,8]$. Therefore, it is necessary to implemented control strategy in spray dryer. One of the most common stable control used is closed loop process control [12]. One of the consideration in process control is control tuning. Process control tuning is a key role in ensuring that the plant performance satisfies the operating objectives. The performance goals of better set-point tracking and disturbance rejection should be balanced against the robustness of stable operation over a wide range of conditions.

An effective feedback control system is expected to be stable and capable of causing the system output ultimately to attain its desired set-point value. The approach of this system output to desired set-point should neither be too sluggish, nor too oscillatory.

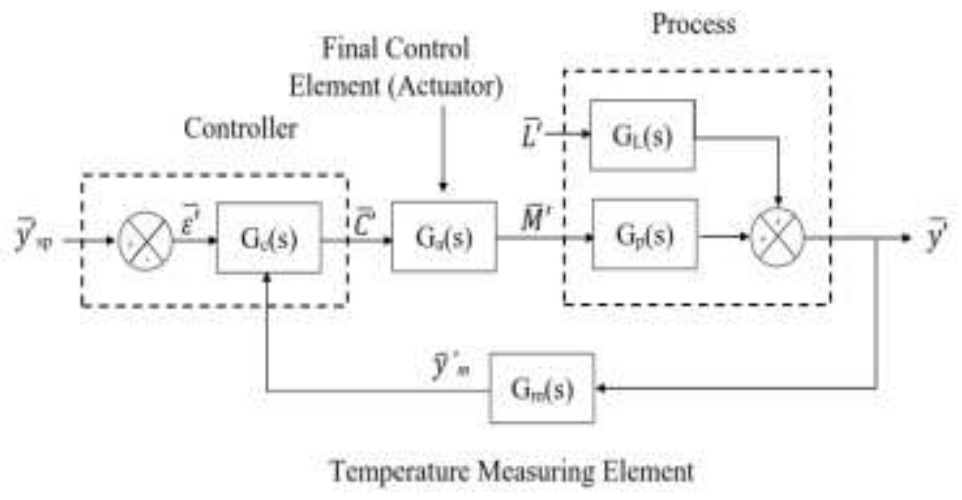

Fig. 5 Closed Loop Process Control

Generalized process and corresponding feedback control loop block diagram can be seen in Figure 5. The process has the disturbances input $L$ from the process load and a measurable variable input $M$. In addition, the controlled variable as an output $y$. The changes of the disturbance $L$ is unpredictably. The goal is to adjust the measurable variable $M$ so that the output variable $y$ as steady as possible. There are 3 steps in the feedback control system:

a. Measuring the value of the output, $y_{m}$

b. Comparing $y_{m}$ to the set point, $y_{s p}$ and determining the deviation $\varepsilon=y_{s p}-y_{m}$

c. Deviation processed by controller to give an output signal $C$ to the final control element. The final control element makes change to the measurable control variable $M$.

There are two typical measuring temperature devices: thermo-resistive and thermoelectric. Thermo-resistive sensors such as resistance temperature detectors, or thermistors 
will change the resistance when the ambient temperature varies. Whereas thermo-electric device such as thermocouples will produce a voltage proportional to the surrounding temperatures [13]. The final control elements are typically valves or motors depending upon situation. The equation for the system will be:

a. Process: $\overline{y^{\prime}}=G p \bar{M}^{\prime}+G l \overline{L^{\prime}}$

b. Temperature Measuring Element: $\overline{y^{\prime}} m=G m \overline{y^{\prime}}$

c. Comparator: $\bar{\varepsilon}^{\prime}=\overline{y^{\prime}} \mathrm{sp}-\overline{y^{\prime}} \mathrm{m}$

d. Controller Output: $\overline{C^{\prime}}=G c \overline{\varepsilon^{\prime}}$

e. Final Control Element: $\overline{M^{\prime}}=G a \bar{C}^{\prime}$

A set of transfer functions that relate the output y' to the two inputs y'sp and L' would be:

and

$$
\overline{y^{\prime}}=\text { GSetPoint } \cdot \bar{y}^{\prime} \mathrm{sp}+\text { GLoad } \cdot \bar{L}^{\prime}
$$

so

$$
\begin{aligned}
& \overline{y^{\prime}}=G p G a G c\left(\bar{y}^{\prime} \mathrm{sp}-G m \overline{y^{\prime}}\right)+G L \overline{L^{\prime}} \\
& \bar{y}^{\prime}=\frac{G p G a G c}{1+G p G m G a G c} \bar{y}^{\prime} \mathrm{sp}+\frac{G L}{1+G p G m G a G c} \overline{L^{\prime}}
\end{aligned}
$$

and

$$
\text { GSetPoint }=\frac{G p G a G c}{1+G p G m G a G c}
$$

$$
\text { Gload }=\frac{G L}{1+G p G m G a G c}
$$

In the closed loop feedback controller there are three major type of feedback controller tuning, the controllers are proportional controller $(\mathrm{P})$, proportional-integral controller $(\mathrm{PI})$ and proportional-integral-derivative controller (PID). $P$ controller can achieve acceptable offset with moderate value and it usually used for gas pressure and liquidlevel control. On the other hand, to provide sufficiently small steady-state errors PI controllers are necessary to be used. In addition, I controller make the speed of the closed-loop system remains satisfactory. PID controller usually in used in order to increase the speed of the closed-loop response and retain robustness.

PID controllers are widely used in practice more than 60 years. The control algorithm is in fact are same. The PID controller is a standard and proved solution for the most of industrial control applications. Over the years, there are many formulas derived to tune the PID controller for adjusted parameters and achieved optimum value. There are three parameters must be tuning to achieved optimum value. The Table I shows parameters of the PID controller.

Table I. Parameters of PID Controller

\begin{tabular}{|c|c|}
\hline Symbol & Parameter \\
\hline$K c$ & Proportional \\
\hline$\tau_{I}$ & Integral \\
\hline$\tau_{D}$ & Derivative \\
\hline
\end{tabular}

After PID controller has been selected, there are need approaches to use for tuning a controller and get the optimum parameters. It has many approaches for tuning and general approaches are use simple criteria such as the one-quarter decay ratio, minimum settling time, minimum largest error and so on.

The most used controller tuning was published by Ziegler and Nichols (1942) are used to provide closed-loop responses that have one-quarter decay ratio with minimum 
settling time and minimum largest error. The PID controller in many cases will save energy in more than 40\% [14]. The Ziegler-Nichols method is more robust because it does not require a specific process model. In order to tune a controller using the ZieglerNichols method the Integral and Derivative elements of the PID controller are ignored. The Proportional element is used to find a Kc that will sustain oscillation. This value is considered the ultimate gain $\mathrm{Kcu}$. The period of oscillation is the ultimate period $\mathrm{Pu}$. Consequently, Ziegler-Nichols settings are reasonable to be applied in controller tuning using Table II.

Table II. Zieglar-Nichols PID Controller Setting

\begin{tabular}{|c|c|c|c|}
\hline & $\mathrm{P}$ & $\mathrm{PI}$ & PID \\
\hline $\mathrm{K}_{\mathrm{c}}$ & $0.5 \mathrm{~K}_{\mathrm{cu}}$ & $0.45 \mathrm{~K}_{\mathrm{cu}}$ & $0.6 \mathrm{~K}_{\mathrm{cu}}$ \\
\hline$\tau_{\mathrm{I}}$ & - & $\mathrm{P}_{\mathrm{u}} / 1.2$ & $\mathrm{P}_{\mathrm{u}} / 2$ \\
\hline$\tau \mathrm{D}$ & - & - & $\mathrm{P}_{\mathrm{u}} / 8$ \\
\hline
\end{tabular}

This Ziegler- Nichols method consists of two steps:

a. Determination of the dynamic characteristics of the control loop

b. Estimation of the controller tuning parameters that produce a desired response for the dynamic characteristic from the first step.

The dynamic characteristics of the process is the ultimate gain of a $\mathrm{P}$ controller and the ultimate period of oscillation of the loop. It usually determinate the ultimate gain and period from the actual process by these procedures:

c. First, switching off the I and D modes of the feedback controller so as to have only $\mathrm{P}$ controller.

d. After that increase the gain P until the loop oscillates with constant amplitude. Record the value of the gain that produces sustained oscillation. As to prevent the loop from going unstable, smaller increments in gain are made as the ultimate gain is approached.

e. From a time recording of the controlled variable such as the Figure 6, the period of oscillation is measured and recorded as $\mathrm{T}$ the ultimate period.

For the desired response of the closed loop, the Ziegler-Nichols method specified a decay ratio of one-fourth. The decay ratio is the ratio of the amplitudes of two successive oscillations. It should be independent of the input to the system and should depend only on the roots of the characteristic equation for the loop. The tuning relationship are intended to minimize the Integral error, their use is referred to as minimum error integral tuning. However, the Integral of the error cannot be minimized directly, because a very large negative error would be the minimum. Figure 6 shows the error Integrals for disturbance and for set point changes. 

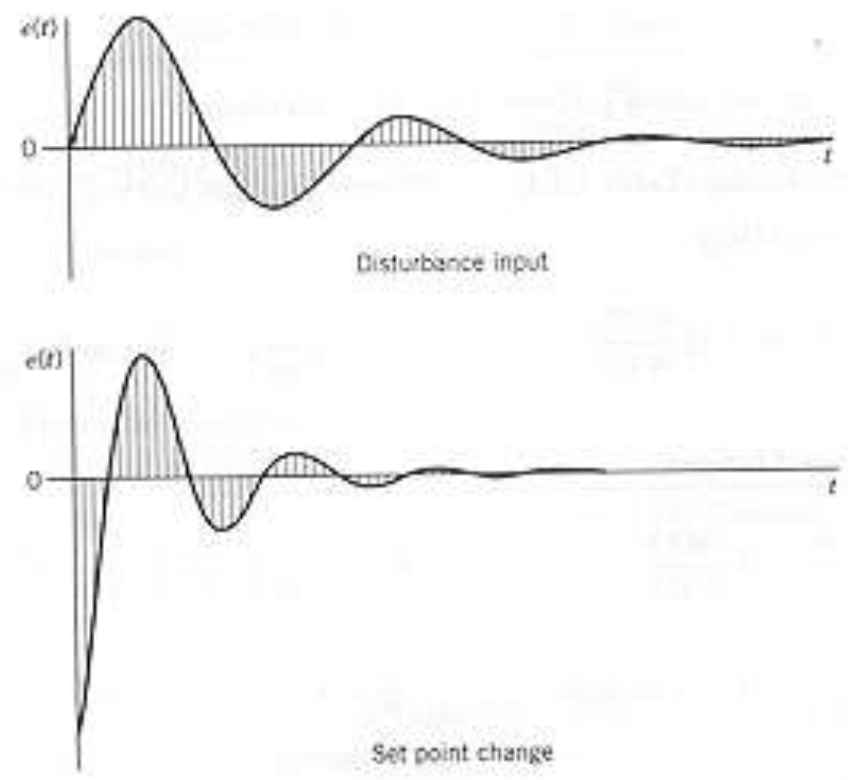

Fig. 6 Error Integrals on Disturbance and on Set Point Changes

\section{PROPOSED METHOD}

The spray dryer machine used in this study was designed in 2015 which mostly made from food grade stainless steel ST304 as seen in Figure 7. The energy sources are the combination of electrical energy and liquid petroleum gas (LPG) energy which are commonly used in Indonesia. The electrical energy consumption is $1200 \mathrm{~W}$ att and the LPG energy need approximately $1 \mathrm{~kg} /$ hour. Electrical energy is needed for air compressor and for control system. Whereas LPG energy is for heating the burner to blow the compressed air through the heat exchanger. The motor actuator from the system is used to increase or decrease the fire torch from the burner.

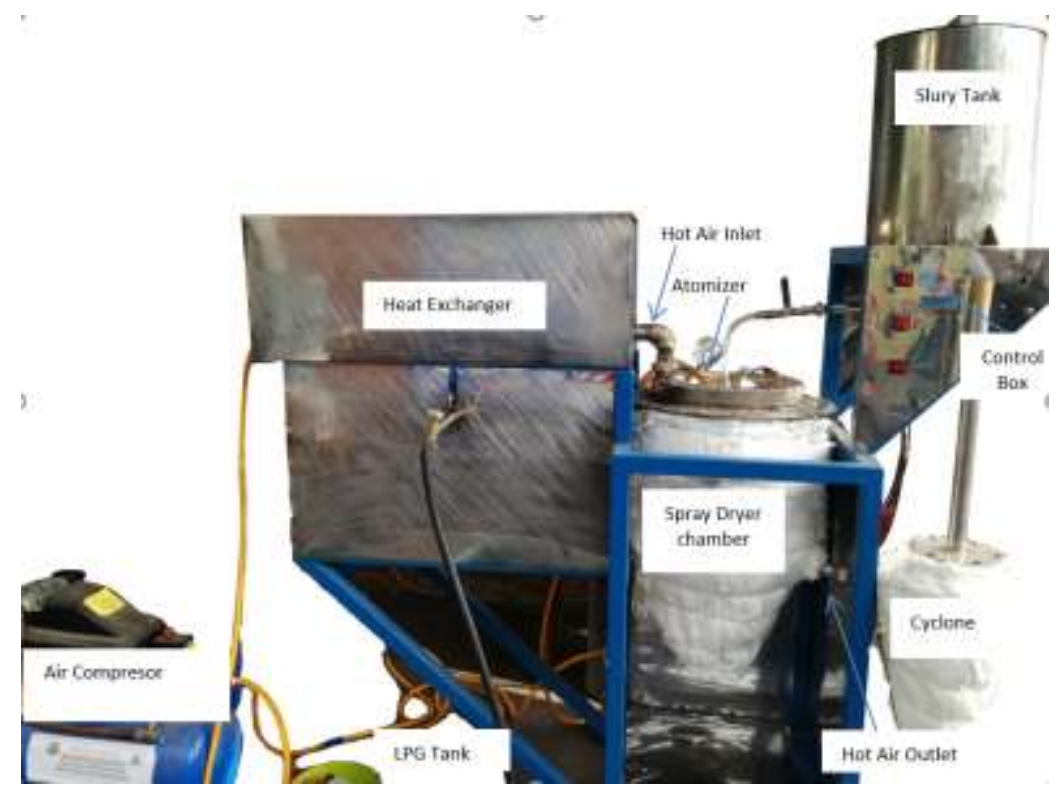

Fig. 7 Physical Look of Spray Dryer for this Study

The heated system is a certain space in the spray dryer chamber where the inlet temperature is kept to a certain value temperature with a certain range of hot air outlet 
temperature. The heat-exchanger supplies thermal energy to the spray dryer chamber. The spray dryer chamber is separated from the other environment by a temperature insulation wall. The temperature sensors consist of two RTD which are placed in the inlet and the other is placed in hot air outlet.

Figure 8 showing the block diagram spray dryer chamber temperature electronic controller. The compressed air from the compressor is used to supply air for the heat exchanger and for atomizer. In the atomizer there will be mixed between slurry from slurry tank with compressed air which will dispersed the slurry into the fog form. This fog form slurry will be contacted with hot air from the hot air inlet, which will change the hot air temperature in the drying chamber. Microcontroller is used as a main controller of the system with Ziegler- Nichols PID controller algorithm in it. Both RTD are read by microcontroller and both temperature of the hot air inlet and hot air outlet be displayed in the LCD display. The temperature setting done by keying the needed temperature from keypad. The Ziegler-Nichols PID controller was used to control the position of the motor actuator to increase or to decrease the fire torch from the burner of the heat exchanger.

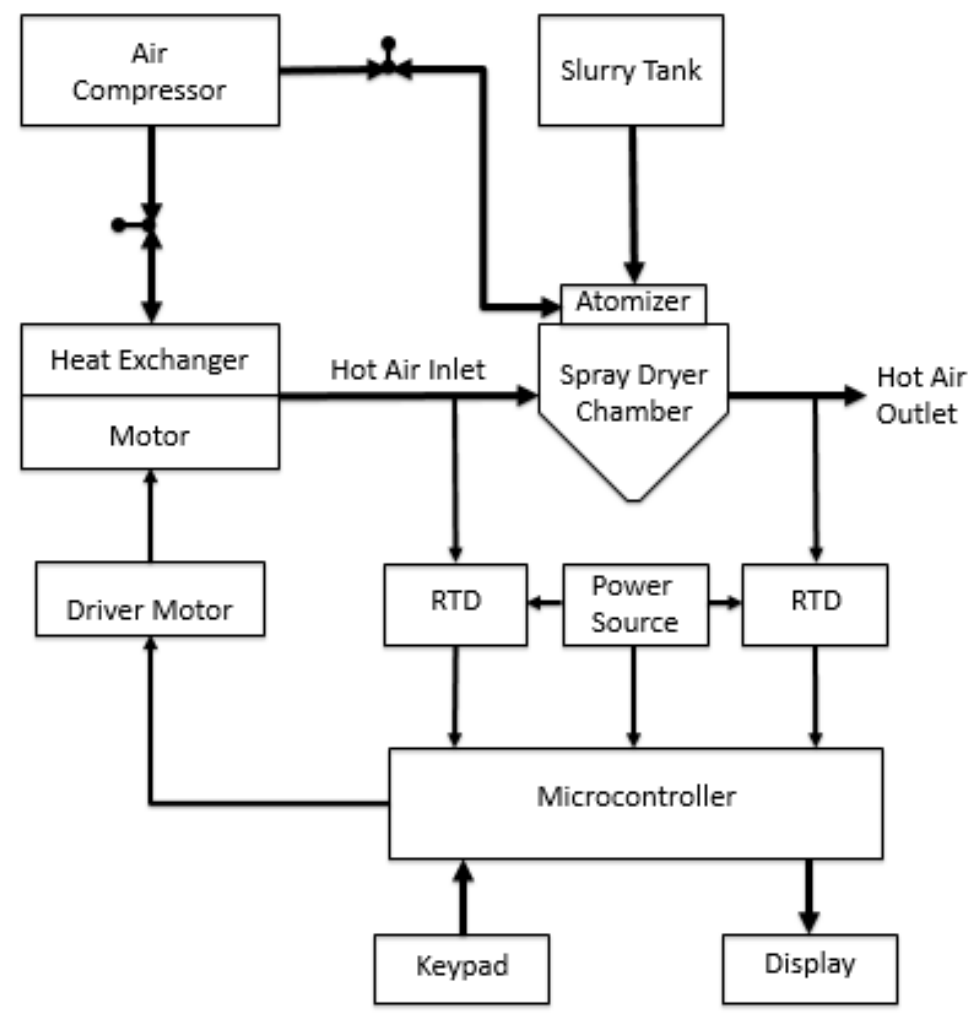

Fig. 8 Block Diagram Spray Dryer Chamber Temperature Electronic Controller

The earlier study by the authors [15] has shown that product quality can be predict using the condition on the drying chamber process. This will still be used in this study. The changing of the flow disturbances was evaluated due to the performance of the electronic Ziegler- Nichols PID controller. In addition, the effect of the slurry thickness and air pressure to the atomizer were also observed due to the spray dryer machine performance.

\section{RESULTS AND DISCUSSION}

Spray dryer machine designed in this study is still using an experimental approach. One reason for this is that the process of spray dryer itself has certain characteristics, such 
as rapid heating and mass transfer, which challenged the principles of modeling perspective. In addition, control of the process is difficult because of the unavailability of product quality measurement directly, for example: particle size.

In the process of drying in the spray dryer technology, slurry-liquid is brought into contact with a hot air to evaporate the water from slurry-liquid with the addition of certain solvents. Results dryer product is shaped particles called as a powder. In designing the spray dryer machine, the timing of entering both the slurry and the hot air from the heat exchanger into the spray dryer chamber is important. Granular particles should remain in the spray dryer chamber long enough for the evaporation of the water from the slurryliquid but not too long to cause degradation of the product quality. The controller used in this study can be seen in Figure 9.

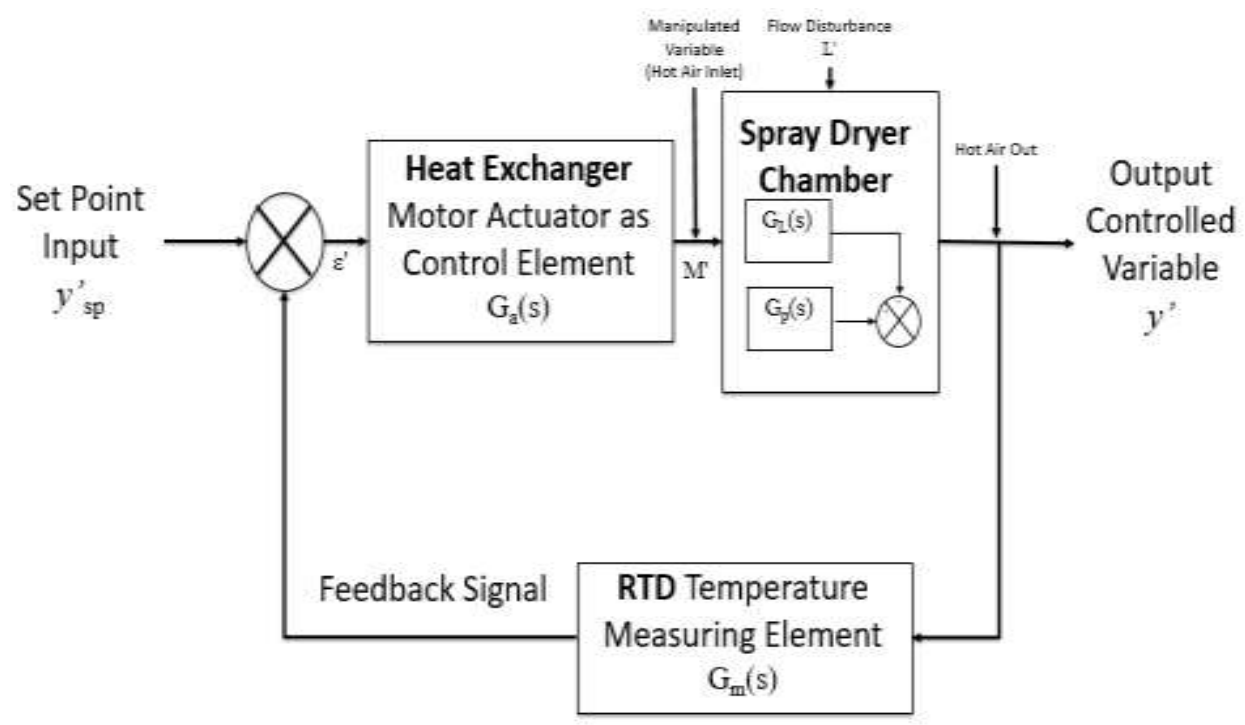

Fig. 9 Block Diagram of Spray Dryer Closed Loop Process Control

The spray dryer closed loop process control, as seen in Figure 9, used in this study using set point input $y_{s p}$ to be compared with the feedback signal $y_{m}$, measured by RTD from hot air outlet, to determine the deviation $\varepsilon=y_{s p}-y_{m}$. The deviation processed by controller to give an output signal to the final control element. The purpose of the controller is to adjust the measurable variable $M$ so that the output variable $y$ as steady as possible due to the system disturbances input $L$ and a measurable variable input $M$. The PID Ziegler-Nichols controller tuning parameters that produce a desired response for the dynamic characteristic of the process is the ultimate gain of a $\mathrm{P}$ controller and the ultimate period of oscillation of the loop. It determinated the ultimate gain and period from the actual process by switch off the I and D modes of the feedback controller so as to have only $\mathrm{P}$ controller. The spray dryer closed loop process model analysis using Excel Spreadsheet. The value of the tuning parameters obtained by period of oscillation. The graphical simulation is shown in Figure 10 and Figure 11. Ziegler-Nichols rules are entered as Excel formula. 


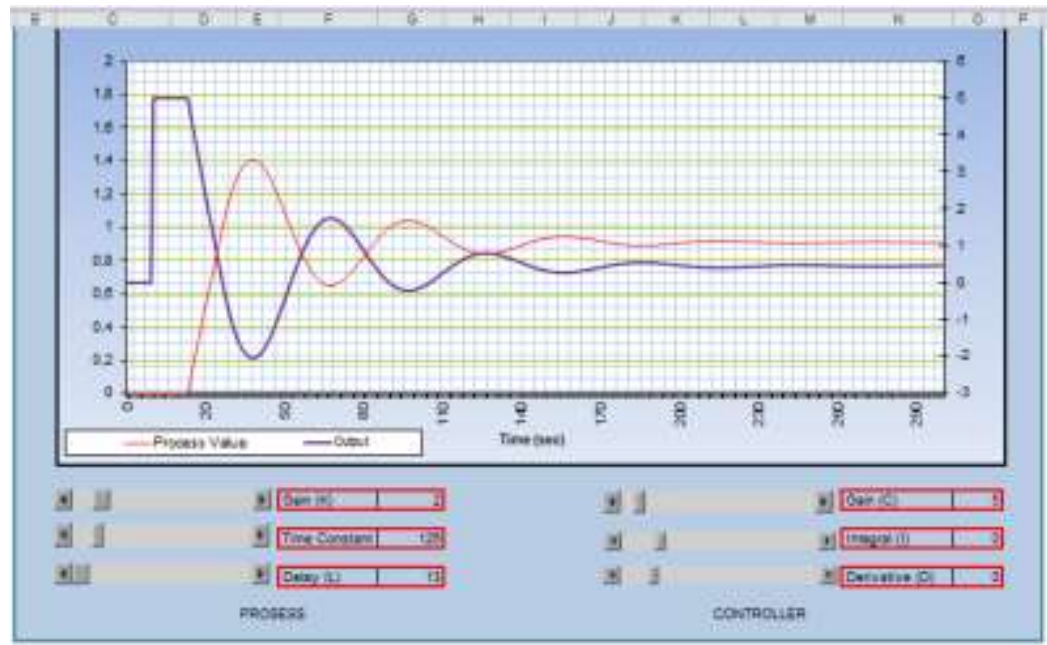

Fig. 10 Output Signal and Process Value at only P Controller

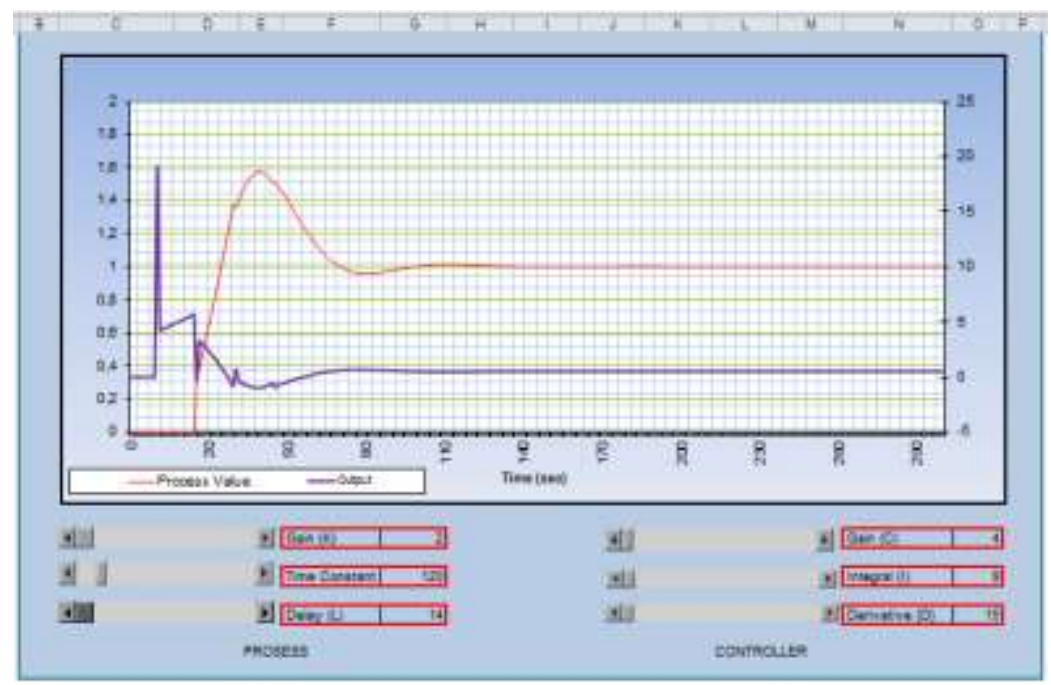

Fig. 11 Output Signal and Process Value at Optimum PID Controller

For the desired response of the closed loop, the Ziegler-Nichols method specified independence of the input to the system and depend only on the roots of the characteristic equation for the loop. The tuning relationship minimize the integral tuning, this tuning is then used as the setting controller value for the spray dryer machine testing. The spray dryer machine test using fresh tomato to be dried. Postharvest losses in tomato are a major problem for tomato farmers in Malang-Indonesia because farmers getting very low prices during the tomato season and tomato can't stand more than 7 days in a room temperature. Processing fresh tomato to become tomato powder extend storage life, reduce bulk for storage, transport, and packaging. On the other hands tomato powder, one of the most important processed vegetable, has a big potential for processing food industries in making ketchup, soups, and sauces. In addition, tomatoes are the major sources of lycopene whereas the heat from drying process break the cell walls and increasing the lycopene content [16][17]. Lycopene is a powerful antioxidant that can protect and repair body from damage caused by various diseases. That is the reason many study on the tomato powder production has been done. Tomato powder product using spray dryer technology has been study extensively as in Table III. 
Table III. Spray Dryer Studies on Producing Tomato Powder

\begin{tabular}{|c|l|l|}
\hline Refs & \multicolumn{1}{|c|}{ Problem/Objective } & \multicolumn{1}{|c|}{ Result/Claim } \\
\hline$[16]$ & $\begin{array}{l}\text { Spray drying para-meters for the maximum } \\
\text { recovery of fruit powder from different } \\
\text { tomato varieties grown in Din Digul } \\
\text { District-India }\end{array}$ & $\begin{array}{l}\text { Different tomato variety from different grown } \\
\text { district produce different quality of tomato } \\
\text { powder }\end{array}$ \\
\hline$[17]$ & $\begin{array}{l}\text { Stability of lycopene during spray drying of } \\
\text { tomato pulp }\end{array}$ & $\begin{array}{l}\text { The heat from drying process break the cell } \\
\text { walls and increasing the lycopene content }\end{array}$ \\
\hline$[19]$ & $\begin{array}{l}\text { Spray drying tech-nology for producing } \\
\text { fruit powders from tomatoes and tamarillo. }\end{array}$ & $\begin{array}{l}\text { Hot inlet air temperatures of } 160^{\circ} \mathrm{C} \text { at a } \\
\text { constant outlet temperature of 90 } \\
\text { observed as the optimum conditions for the } \\
\text { maximum recovery of tomato powder }\end{array}$ \\
\hline$[20]$ & $\begin{array}{l}\text { Spray-dried tomato powder: reconstitution } \\
\text { properties and color. }\end{array}$ & $\begin{array}{l}\text { Hot air inlet temperature 220 }{ }^{\circ} \mathrm{C} \text { produced the } \\
\text { powders with a higher color index }\end{array}$ \\
\hline$[21]$ & $\begin{array}{l}\text { Effect of malto-dextrin addition during } \\
\text { spray drying of tomato pulp in dehumidified } \\
\text { air }\end{array}$ & $\begin{array}{l}\text { Optimum temperature of drying inlet } 130,140, \\
\text { and } 150^{\circ} \mathrm{C} \text { with tomato pulp solids in addition } \\
\text { with maltodextrin }\end{array}$ \\
\hline T22] & $\begin{array}{l}\text { The effects of the different drying } \\
\text { addition during spray drying of sumac } \\
\text { extract }\end{array}$ & $\begin{array}{l}\text { Temperature, maltodextrin, and the interaction } \\
\text { between temperature and maltodextrin have an } \\
\text { important effect on the performed analysis }\end{array}$ \\
\hline
\end{tabular}

Powdered tomato was produced by spray drying the tomato pulp with hot air inlet temperature $\left(220^{\circ} \mathrm{C}\right)$ produced the powders with a higher color index [20]. The tomato pulp is a preprocessed by bleaching method. Whereas, other study found that Maltodextrin addition improved powder hygroscopicity and solubility with optimum temperature of drying inlet 130,140 , and $150^{\circ} \mathrm{C}$ [21]. While other found that temperature, maltodextrin, and the interaction between temperature and maltodextrin have an important effect on the performed analysis [22]. Those studies were used as foundation on setting of the spray dryer machine. Figures 12, 13, and 14 are some experiments in obtaining the drying process values.

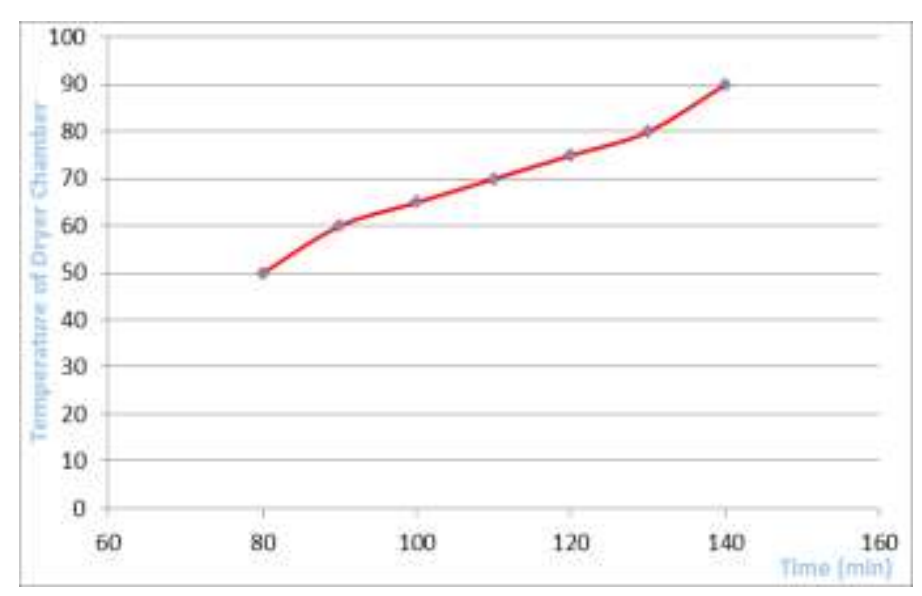

Fig. 12 Time to Get Stable Spray Dryer Chamber Temperature

Turning on the spray dryer machine firstly by turning on the LPG burner of the heat exchanger and then the air compressor. It takes time to be able to make the dryer chamber to get stable temperature as seen in Figure 12. It took 60 minutes to increase the dryer chamber to increase to temperature of $90^{\circ} \mathrm{C}$ and 90 minutes to get temperature of $140^{\circ} \mathrm{C}$. 
At this temperature the spray dryer chamber is ready to accept the dispersion of the slurry from the slurry tank.

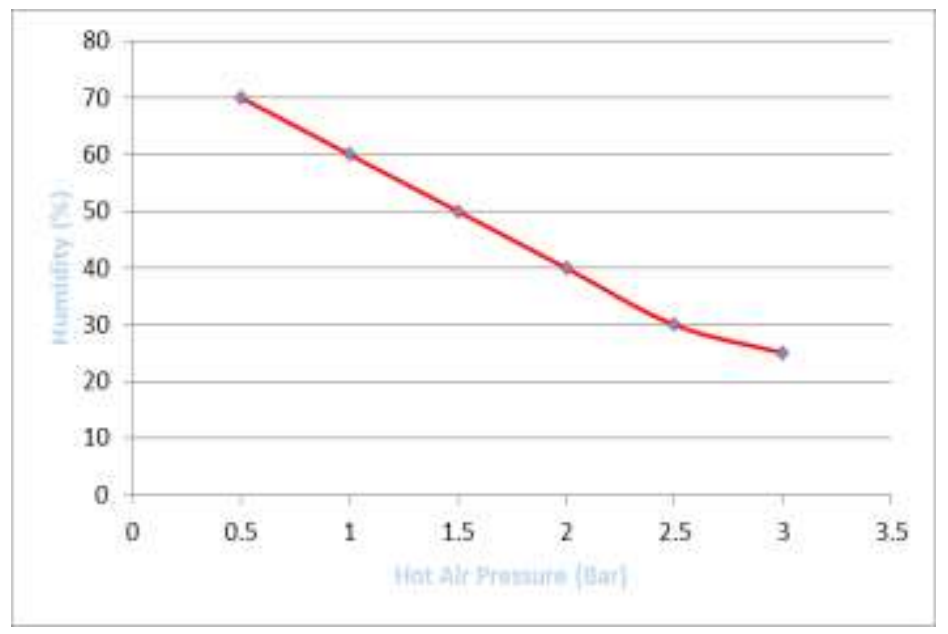

Figure 13. Variation of Hot Air Inlet Pressure against Hot Air Outlet Humidity

Setting the hot air outlet from the spray dryer chamber to $100^{\circ} \mathrm{C}$ and hot air inlet to $150^{\circ} \mathrm{C}$ with the slurry flow rate at $5 \mathrm{ml} / \mathrm{min}$ changing the hot air pressure has change the hot air outlet humidity. The humidity of the hot air outlet indicates the dampness of the powder product. The less the humidity the better the powder quality. Figure 13 shows that the changing of hot air pressure will change the humidity of the hot air outlet. At the hot air pressure 0.5 bar the humidity of the hot air outlet is $73 \%$. Increasing the hot air pressure to 3 bar has decrease the humidity to $25 \%$. The graph shows that increasing the hot air inlet pressure has decrease the hot air outlet humidity which indicate the powder quality.

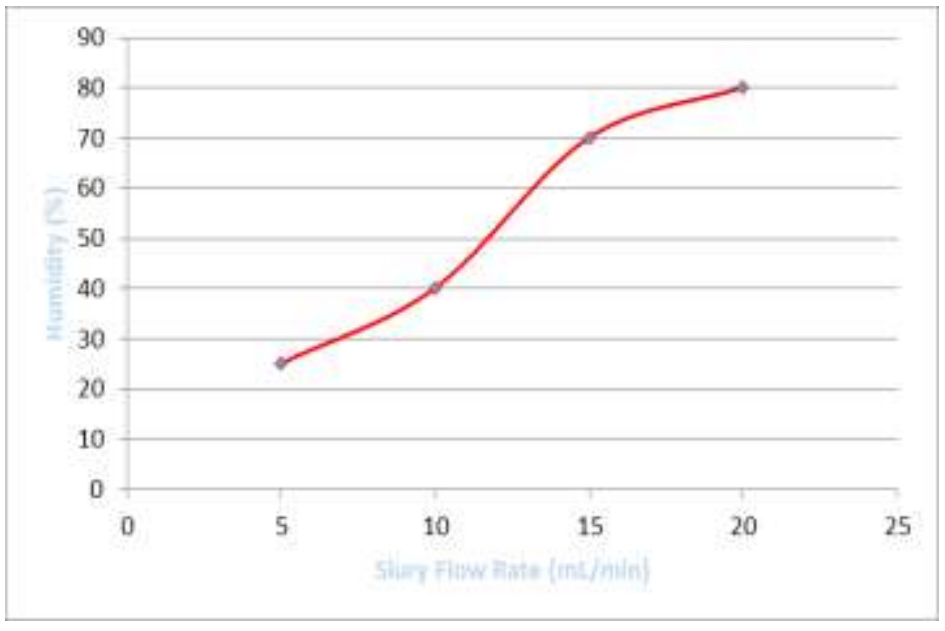

Fig. 14 The Variation Slurry Flow Rate against Humidity

The spray dryer machine principally is used to remove the water content from the sprayed slurry in the chamber. The removal of water content needed to be done as fast as possible, which can be obtained by increasing the hot air inlet temperature. Increasing the hot air temperature will change the nutrition quality of the product, therefore the temperature can't be change to be too hot. Figure 14 show the experiment on the slurry flow rate. The hot air inlet set to temperature of $150^{\circ} \mathrm{C}$ and pressure of 3 bar. It shows that at the slurry flow rate of $5 \mathrm{~mL} / \mathrm{min}$ the humidity of the hot air outlet is $25 \%$, increasing the 
slurry flow rate to $20 \mathrm{~mL} / \mathrm{min}$ increase the humidity of the hot air outlet to $80 \%$. From this experiment indicate that increasing the slurry flow rate will increase the hot air outlet humidity which means decreasing the powder product quality. The next experiment is on the fresh tomato powder product.

Table IV. Spray Drying Testing for Tomato Powder with No Addition of MaltoDextrin

\begin{tabular}{|c|c|c|c|}
\hline $\begin{array}{c}\text { Hot Air Inlet } \\
\text { Temp }\left({ }^{\circ} \mathrm{C}\right)\end{array}$ & $\begin{array}{c}\text { Hot Air Outlet } \\
\text { Temp }\left({ }^{\circ} \mathrm{C}\right)\end{array}$ & $\begin{array}{c}\text { Slurry Flow Rate } \\
(\mathrm{mL} / \text { minutes })\end{array}$ & Results \\
\hline 150 & 100 & 5 & Sticky Powder \\
\hline 140 & 100 & 5 & Sticky Powder \\
\hline 130 & 100 & 5 & Sticky \\
\hline
\end{tabular}

Table V. Spray Drying Testing for Tomato Powder with Addition of 40 gram MaltoDextrin

\begin{tabular}{|c|c|c|c|}
\hline $\begin{array}{c}\text { Hot Air Inlet } \\
\text { Temp }\left({ }^{\circ} \mathrm{C}\right)\end{array}$ & $\begin{array}{c}\text { Hot Air Outlet } \\
\text { Temp }\left({ }^{\circ} \mathrm{C}\right)\end{array}$ & $\begin{array}{c}\text { Slurry Flow Rate } \\
(\mathrm{mL} / \text { minutes })\end{array}$ & Results \\
\hline 150 & 100 & 5 & Powder \\
\hline 140 & 100 & 5 & Sticky Powder \\
\hline 130 & 100 & 5 & Sticky Concentrate \\
\hline
\end{tabular}

Those studies in Table III and the drying process experiments as seen in Figures 12, 13 , and 14 were used as foundation on setting temperature of hot air inlet and hot air outlet to be 130,140 , and $150^{\circ} \mathrm{C}$ with addition of Maltodextrin 40 gram to 1 liter of fresh pulp slurry. The preprocessing in making the tomato slurry in these 4 steps:

a. Washing the fresh tomato using clean drinking water.

b. Boiling a water and put the fresh tomato in it for 3 minutes.

c. Pulping the tomato and strain it with clothing filter

d. Adding water, maltodextrin, and tomato pulp to make a slurry mixture and putting it into the slurry tank.

After putting slurry into the tank then set the hot air inlet temperature to be in range of 130 and $150^{\circ} \mathrm{C}$ with the pressure of $3 \mathrm{bar}$, whereas hot air outlet was set to $100^{\circ} \mathrm{C}$, the result shown in Table IV for no addition of MaltoDextrin and Table 5 with the addition of MaltoDextrin.

From Table $\mathrm{V}$ it shows that with the addition of Maltodextrin the powder quality increase, however adding more Maltodextrin will make the tomato powder has less natural flavor. When the hot air inlet set in $130^{\circ} \mathrm{C}$ and hot air outlet set in $100^{\circ} \mathrm{C}$ with slurry flow rate of $5 \mathrm{~mL} / \mathrm{min}$ the result of the process was a sticky concentrate. This means that the chamber temperature need to be increased, whereas increasing chamber temperature means increasing energy consumption. Increasing the hot air inlet to $150^{\circ} \mathrm{C}$ has shown that the result of the process was a powder. Increasing hot air temperature make the powder quality increase, but the energy consumption of making the powder increased. 


\section{CONCLUSION}

This paper has presented the design and experimental investigation of an electronics spray dryer process control especially for the purpose of preserving fresh tomato. In the process of drying in the spray dryer technology, slurry-liquid is brought into contact with a hot air inlet from heat exchanger to evaporate the water from slurry-liquid in the spray dryer chamber. Spray dryer product is shaped particles called as a powder. In designing the spray dryer machine, the timing of entering both the slurry and the hot air into the spray dryer chamber is important. The electronics process controller is implemented to convert fresh fruit or vegetable into a fruit or vegetable powder form of a desired quality at a minimum cost. A simulation of a PID controller with Ziegler-Nichols tuning in the form of an Excel spreadsheet give the parameters used for the machine. The experimental investigation has shown that for fresh tomato drying process, the addition of Maltodextrin has increase the powder quality. When the hot air inlet set in $150^{\circ} \mathrm{C}$ and hot air outlet set in $100^{\circ} \mathrm{C}$ with slurry flow rate of $5 \mathrm{~mL} / \mathrm{min}$ the result of the process was a powder. Increasing hot air temperature make the powder quality increase, but the energy consumption of making the powder has also increased. Based on this study, analyzing physical and chemical properties of the spray dryer product are needed in order to provide a good powder quality. The energy consumption analysis is also needed to predict the economical operation of the designed machine.

\section{ACKNOWLEDGMENT}

We want to thank to the director of State Polytechnic of Malang for financing this article publication. In addition, we also want to thank to the Indonesia Department of Research, Technology, and Higher Education for the 2015-2016 research grants in RUPT scheme. We also want to thank to the faculty of Electronics Engineering Technology, State Polytechnics of Malang for their support.

\section{REFERENCES}

[1] Wirawan, B., "Price Fluctuation, Price Transmission, and Marketing Margin of Vegetables and Fruits", Agricultural Policy Analysis. Volume 5 Dec. 4, (2007): 358-373.

[2] Saifullah, M., Yusof, Y.A., Chin, N.L., Aziz, M.G., Mohammed, M.A.P. and Aziz, N.A., "Dissolution profiling and its comparison of natural fruit powder effervescent tablets", Journal of Food Engineering, 178,, (2016): 60-70.

[3] Khapre, A.P., Satwadhar, P.N. and Syed, H.M., "Studies on processing technology and cost estimation of fig (Ficus carica L.) fruit powder enriched Burfi (Indian cookie)", Journal of Applied and Natural Science, 7(2), (2015): 621-624.

[4] Snyder, J., Ijumba, C., Tschirley, D. and Reardon, T., "Local Response to the Rapid Rise in Demand for Processed and Perishable Foods: Results of an Inventory of Processed Food Products in Dar es Salaam", Innovation Lab for Food Security, Michigan State University, East Lansing, MI, Tanzania Policy Research Brief, (2), (2015).

[5] State Polytechnic of Malang, 2012. Research Master Plan Year 2012-2016. Malang: Unpublished.

[6] Petersen, L.N., Jorgensen, J.B. and Rawlings, J.B., "Economic optimization of spray dryer operation using nonlinear model predictive control with state estimation", IFAC-PapersOnLine, 48(8), (2015): 507-513.

[7] Snyder, J., Ijumba, C., Tschirley, D. and Reardon, T., "Local Response to the Rapid Rise in Demand for Processed and Perishable Foods: Results of an Inventory of Processed Food Products in Dar es Salaam", Innovation Lab for Food Security, Michigan State University, East Lansing, MI, Tanzania Policy Research Brief, (2), (2015).

[8] Atkins, M. et al., "Integrating Heat Recovery from Milk Powder Spray Dryer Exhausts in The Dairy Industry", Applied Thermal Engineering Journal. vol. 31, (2011): 2101-2106.

[9] Toneli, M. et al., "Effect of the Outlet Air Reuse on Thermal Efficiency of a Pilot Plant Spray Dryer with Rotary Atomizer", Chemical Engineering Trans., vol. 32, (2013): 241-246.

[10] Langrish, T. et al., "The Assessment of a Characteristic Drying Curve for Milk Powder for Use in Computational Fluid Dynamics Modeling”, Chemical Engineering Journal, Vol. 84, (2001): 69-74.

[11] Wolovick, W., “Automatic Control Systems: Basic Analysis and Design”, New York: Holt, Rinehart and Winston, Inc., (1994): 167-177. 
[12] Bartelt, T., "Industrial Control Electronics: Devices, Systems, and Applications", New York: Thomson Delmar Learning, (2006): 234-241.

[13] Ordaz, P., Santos-Sánchez, O.J., Rodríguez-Guerrero, L. and González-Facundo, A., "Nonlinear stabilization for a class of time delay systems via inverse optimality approach", ISA transactions, (2016).

[14] Parastiwi, A., "Design of spray dryer process control by maintaining outlet air temperature of spray dryer chamber", In Intelligent Technology and Its Applications (ISITIA), 2016 International Seminar, IEEE, (2016) July: 619-622.

[15] Tapiero, H., Townsend, D.M., and Tew, K.D, "The role of carotenoids in the prevention of human pathologies", Biomed, Pharmacother, http://dx.doi.org/10.1016/j.biopha.2003.12.006. PubMed, 58 (2), (2004); 100-110.

[16] Siddick, A. and Ganesh, S., "Spray drying parameters for the maximum recovery of fruit powder from different tomato varieties grown in Dindigul District", International Journal of Scientific and Research Publications, 3(2), (2013); pp.1-2.

[17] Goula, A.M., and Adamopoulos, K.G., "Stability of lycopene during spray drying of tomato pulp. Lebensm", Wiss. Technol, http://dx.doi.org/10.1016/j.lwt.2004.07.020, 38 (5), (2005): 479-487.

[18] Tontul, I., Topuz, A., Ozkan, C. and Karacan, M., "Effect of vegetable proteins on physical characteristics of spray-dried tomato powders", Food Science and Technology International, 22(6), (2016): 516-524.

[19] Siddick, S.A. and Ganesh, S., "Spray drying technology for producing fruit powders from tomatoes and tamarillo", In XXIX International Horticultural Congress on Horticulture: Sustaining Lives, Livelihoods and Landscapes (IHC2014): 1120, (2014) August: 343-348.

[20] Sousa, A.S.D., Borges, S.V., Magalhães, N.F., Ricardo, H.V. and Azevedo, A.D., "Spray-dried tomato powder: reconstitution properties and colour", Brazilian Archives of Biology and Technology, 51(4), (2008): 607-614.

[21] Goula, A.M. and Adamopoulos, K.G., "Effect of maltodextrin addition during spray drying of tomato pulp in dehumidified air: II", Powder properties, Drying Technology, 26(6), (2008): 726-737.

[22] Caliskan, G. and Dirim, S.N., "The effects of the different drying conditions and the amounts of maltodextrin addition during spray drying of sumac extract”, Food and Bioproducts Processing, 91(4), (2013): 539-548. 